\title{
Disaster management: lessons from immediate responses to the tsunami
}

\begin{abstract}
There are many lessons learnt from the immediate reactions of people in the aftermath of the vast destruction from the giant waves that hit Sri Lanka. Reactions of victims fell between extremes of resilience and helplessness. Responses of those not directly harmed illustrated the two extremes-selflessness and depravity. These responses offer insight into how we live and how we react to situations, and also to an extent how we should be reacting. Among these is that helpers should respect and involve, from the inception, the resources within the group or community affected by the disaster. Control of the relief effort to the maximum feasible extent, should be in the hands of those at whom it is directed.
\end{abstract}

\section{Introduction}

Most people are naturally moved to do something when they see a terrible disaster befall others. But what they are driven to do is influenced by many things. If we had a clearer understanding of the different influences that govern our individual and collective responses, we would be able to make them more effective.

\section{Methodology}

I set out to collect, 2 weeks after the giant waves generated by a tsunami hit over half the coastal belt of Sri Lanka, a few of the first-hand and second-hand accounts from people I met during my own efforts to respond to the disaster. The need for urgent action had subsided by then and there was time to reflect on what we had recently heard, seen and been through. The stories led to new thoughts, understanding and confusion. These too I noted against each story. A few of these vignettes, presented here, are in the form in which they were recorded within the first 2 weeks of the disaster.

\section{RESULTS}

Each selected report is followed by my own response, in italics.

Vol. 50, No. 1, March 2005

\section{Reactions of the 'unaffected'}

A baker, who lived far away from the nearest affected coast heard about the event. No sooner he realised the gravity of what had happened, he set about baking as much bread as he could. He then collected a few others and set off towards the coast in a truck laden with food for unknown people, whom he felt would have had nothing to eat for quite some time. Many families had food that day because of him. Such acts of courage, in trying to help others at risk, were many. People had willingly risked their lives and some even died trying to help others. The response of many doctors, who rushed spontaneously to attend to those in need of emergency aid was exemplary.

A contrasting account is that of a group of young men, from just beyond the rim of destruction, who banded together to plunder jewellery, money, wristwatches and the like from the injured, the stricken and the dead. They threatened helpless survivors who did not co-operate. Unconfirmed stories circulated of bodies being mutilated to facilitate faster gathering of booty, and of women being first rescued and then raped.

What makes one man plunder from a wrecked individual that another tries hard to soothe, deserves study. We often look for various biological influences and other individual propensities that predispose to different reactions. My own guess is that the man in the gang that pillaged would have behaved very differently if he were instead in the truck carrying provisions for succour. The prevailing attitude in the small groups or circles to which people belong is probably a more powerful determinant of conduct than individual propensity. It offers, also, greater potential for change.

We need to look at the forces that make subsets of society feel that they do not belong in, or to, the collective enterprise. It is from among the cliques or gangs at the fringes that those who looted mostly came. The easy explanation for such behaviour is poverty and lack of education. But nearly all persons whom I asked opined that such a plunder would not have occurred, say, thirty years ago, although people were then poorer and had no 
more formal education than they have now. The more likely explanation is that the collective human enterprise has fallen victim to the ethos connected to indivisualism and free will.

\section{Reactions of those directly hit}

A woman, immobile and visibly uncared for, was found in a refuge housing several persons who were rendered homeless. This woman was quite alone and it transpired that she had lost all her family members in the deluge. None of the others in the camp was moved enough even sit by her side. Perhaps they too were so shaken that their faculties were not functioning normally.

In another camp housing displaced people, a woman had taken the lead in getting all its members organised. The group shared equitably whatever reached the camp and there was in it a different atmosphere altogether. The woman who took the lead succeeded in getting others to help one another and to deal with issues collectively. She had been recently married and had no children. Her husband too had died in the giant wave.

The difference between these two women has, I am sure, more to do with the kind of people they were, and of course the different scale of losses they suffered. The difference in the response that we see here, may not be attributed to the influence of the groups to which the two individuals belonged.

\section{Phases of adjustment}

A voluntary helper noticed an elderly man attending to something in the rubble of what had been, just the previous day, his house. The visitor found that the man, using an improvised implement, was trying to unscrew a remaining hinge off a frame, from which the torrent had wrenched off the door. He and his wife were collecting the few remaining hinges and nails, he said, "Because we may be able to use these again when we rebuild." This was on the morning after the calamity.

Psychological interpretations such as avoidance and attempted distraction may be provided for this couple's reaction. The simplest explanation is that they had decided just to get on with it. The descriptions of psychological adjustment passing through phases of numbness, denial, depression and so forth are not of as much help in understanding the status of a group or community as they are with individuals. When large numbers are affected, people in different phases of adjustment are crammed together. Allowances need to be made for the variations between individuals.

\section{Prescribed phases of relief efforts}

Helping agencies tended to divide relief needs into phases. Physical needs such as medical assistance, food, water, sanitation and shelter were classified as immediate, psychological needs next and last the reconstruction of houses and livelihood.
This is a logical and sensible order, but it tends to overlook individual needs and capacities. The woman who lost all her family members and could not move herself to get any food, needed psychological help from the very first day. The help needed was simple, perhaps someone to sit beside her, or hold or hug her, nonetheless it is a psychological need that had to be met in the early phase, and likely to be life saving too.

\section{Psychological support}

The anticipated need of professional help to provide psychological support to victims was emphasised from the very beginning in media broadcasts. The general theme was that counsellors and other mental health professionals should quickly reach the traumatised to lend a professional ear, and help them relate their stories over and over again, so as to ease their suffering.

People do relate their traumatic stories over and over again when they grieve. But they do this quite naturally with intimate individuals, and generally not with strangers. In a cataclysm, they may be unavailable. The demand for professionals to get into the scene, almost as a matter of urgency, could have arisen from the recognition of this unusual circumstance. The magnitude of the horror might also have contributed to the feeling that professionals were needed to handle the aftermath.

My impression is that it reflects a latter day social shift, considering provision of human comfort as a service to be delivered by professionals. Where survivors of the ravaged community see themselves a part of the relief effort, there will be at least a few who would have it in them to reach out to their fellows. Space should deliberately be created for willing survivors to be part of the psychological helping resources.

\section{Order, disorder and loss of power}

Victims in camps that were disorganised had a hard time. In the first few days they had to compete among themselves for the provisions that reached their camp. The women felt highly insecure, especially at night. In a few settings, groups of women chose to sleep in turns for protection. Order and protection was established remarkably fast in other camps. The displaced residents in such camps had quietly got their own group organised, attending to each other as best they could, while those officially in charge were getting gripped with the many things that had to be sorted out urgently.

The well-being of people in well organised settings stems from such mundane matters as the equitable sharing of whatever is available. But it has also to do with the sense of collective self-efficacy. In the settings that were well organised from the inception, the displaced community had played a major part in making it so.

People involved in providing relief should make sure that the greatest feasible role is given to the so-called victims, from the start. Able members of the affected 
community must be allowed to participate to the fullest extent that they wish, alongside those who come in from outside. In an ideal world, every possible means would be used to hand over leadership to the people in need of relief.

\section{Blaming}

The government was blamed for not letting people know in time of the impending disaster. Equipment capable of detecting the approaching swell was alleged to have been available but not put in operation due to incompetence. Pinning blame on the Government did not gain momentum, given that other countries including India, the regional technological superpower, had not been able to warn its citizens.

Many stories 'did the rounds' about tsunami warning centres in Hawaii not alerting the Indian Ocean countries at risk. The BBC had apparently quoted the centre in Hawaii as having said that they did not know whom to contact in the countries in peril. Resentment was further aroused by stories that the American military base in the Indian Ocean island of Diego Garcia suffered no casualties or serious damage because they took timely precautions, but did not raise the alarm with the nations at risk.

It is customary to blame the government. The trend seems nowadays to blame the USA next. I suspect that, for the many who are not equipped enough with the requisite theological refinements to circumvent it, the desire to blame a human agency for the suffering stems mostly from the need to avoid a crisis of faith in God.

\section{Other fauna}

Reports were that no animals or birds had died, other than a few of the domesticated. This was surprising since an area badly hit hard was a wildlife sanctuary. The animals in the wild, even lumbering elephants, appeared to have got to safety early enough.

\section{Humans}

The mass media reported, a week or so after the disaster, that the authorities had decided to prohibit construction within 200 metres of the shore. Later broadcasts claimed that the rule applied up to 100 metres. Those who had previously been living within the specified zone would be provided safer alternative land on which houses would be built for them.

Humans in positions of power over others and with scant regard for the helpless should be prevented from making decisions. Victims who possessed only abstract rights over the piece of land they had lived on, were hastily denied permission to rebuild their houses on land they previously occupied. The motivation for this decision could at best be attributed to benevolent, though blindly insensitive, paternalism.

\section{Conclusions}

Well-being in the immediate aftermath of a massive calamity is improved by re-establishing structure as soon as possible. When there is no order, the coarser elements of human nature find it easy to dominate. And the greater the say that those directly affected have in establishing order and structure, the better the visible short-term result. Victims of disaster would do well to strive collectively to gain as much control over their circumstances as feasible, and to get it as soon as possible.

In cataclysmic events, the classical descriptions of phases such as numbness, denial, and anger - through which people's responses to severe trauma are recognised are not helpful enough in understanding the sufferings of affected people. Individuals adjust at different speeds. The struggle for personal survival, loss of physical rootedness, the absence of the close circle with whom pain can be shared and being cheek by jowl with others similarly or worse affected, modify greatly the reactions seen in 'normal grief'.

Mental health professionals must examine whether they have oversold themselves. The public now looks, instinctively, for a professional response where it previously did not, and often where it should not.

Diyanath Samarasinghe, Associate Professor, Department of Psychological Medicine, Faculty of Medicine, Colombo. E-mail: <diyanath1@yahoo.co.uk> (Competing interests: none declared). 